\title{
Degradation of wire electrode during electrical discharge machining of metal matrix composites
}

\author{
A. Pramanik ${ }^{1, *}$, A. K. Basak ${ }^{2}$ \\ ${ }^{1}$ Department of Mechanical Engineering, Curtin University, Bentley, WA, Australia \\ ${ }^{2}$ Adelaide Microscopy, The University of Adelaide, Adelaide, SA, Australia
}

\begin{abstract}
This paper investigated the degradation of wire electrode during electrical discharge machining of SiC reinforced Al-based metal matrix composites (MMCs). MMCs with different size of reinforcements $(0.7,3$ and $13 \mu \mathrm{m})$ as well as corresponding matrix material were machined under similar machining conditions to understand the effect of reinforcement size on the degradation of wire. In addition, pulse-on-time and wire tension were varied to understand the effect of machining parameters and interaction between machining parameters and size of the reinforcements. It was found that initial circular shaped wire deformed during the machining process as curved front and rare edges and two straight side edges irrespective of cutting conditions and workpiece materials. The curved edge at the front and straight side edges take part in material removal and experience sever degradations. The final cross-sectional area of the wire after the machining process is decided by balancing two mechanisms: (i) downward flow of highly malleable soft wire material due to high temperature which increases the diameter of wire electrode and (ii) vaporisation of the wire material at higher temperature which reduces the diameter of wire electrode. These complex processes are affected by machining conditions as well as workpiece materials.
\end{abstract}

Key words: Wire EDM; MMC; wire electrode; deformation.

*Corresponding author

Email: alokesh.pramanik@curtin.edu.au

Phone: + 61892667981 


\section{Introduction}

Electrical discharge machining (EDM) is one of the most extensively used non-conventional material removal processes where electrical discharge is used to machine electrically conductive materials regardless of hardness. Electric discharge generates high thermal energy which removes material by erosion during this process (Ho and Newman 2003). EDM process takes place in a dielectric fluid where the tool is one of the electrodes in the shape of the cavity to be produced and the workpiece to be machined is the other one. The tool is then feed towards the workpiece in a controlled path to produce the shape of the electrode or its movement. The electrode and workpiece do not make direct contact during the EDM process(Ho and Newman 2003, Pramanik 2014). Wire electrical discharge machining (WEDM) is a spark erosion process used to produce complex two and three dimensional shapes. WEDM differs from conventional electrical discharge machining (EDM), as the electrodes are in the form of thin wire with diameter of $0.05-0.3 \mathrm{~mm}$. The wire, which unwinds from a spool, feeds through the workpiece. A power supply delivers high frequency pulses of electricity to the wire and the workpiece. The gap between the wire and workpiece is flooded with a dielectric fluid. Workpiece material is eroded ahead of travelling wire by spark discharges, which are identical with those in conventional EDM (Tosun and Cogun 2003). Particle reinforced metal matrix composites (MMCs) which are hard to machine by traditional methods has the potential to be machined by EDM (Liu, Yue et al. 2009, Meena 2013, Saini, Zahid et al. 2013, Maher, Sarhan et al. 2014). MMCs are different from monolithic materials because of the reinforced ceramic particles which bring better mechanical properties, however also cause higher tool wear and worse surface finish after machining process. Therefore, the complications related to the accurate and optimum machining of MMCs are significant (Pramanik, Zhang et al. 2006, Lal, Kumar et al. 2013, Liu and Wu 2014). Literature review [1-10] indicates that the EDM process is capable of machining MMCs, though lower electrical and thermal conductivities of the reinforced particles affect the material removal rate. EDM produces microscopic craters on the machined surface due to release of random sparks (Muller, Monaghan et al. 1998, Seo, Kim et al. 2006, Liu, Yue et al. 2009). Hung et al. (Hung, Yang et al. 1994) noted that only the electrical current controls the surface roughness and the re-cast layer thickness rises with the rise of pulse-on-times as well as discharge current (Muller, Monaghan et al. 1998). Agrawal et al. (Agrawal and Yadava 2013) investigated electrical discharge machining on $10 \mathrm{wt} . \%$ of $\mathrm{SiC}$ and $10 \mathrm{wt}$.\% of $\mathrm{Al}_{2} \mathrm{O}_{3}$ containing Al-MMCs and modelled the process by artificial neural network. According to their model, material removal rate (MRR) rises with the rise of pulse current, wheel and workpiece speeds and depth of cut. However, the rise of duty factor reduces the MRR. In contrary, roughness ( $\mathrm{Ra}$ ) rises as the depth-of-cut, current, workpiece speed and duty factor 
rise. The rise of the wheel speed reduces surface roughness $(\mathrm{Ra})$. Rozenek et al. (Rozenek, Kozak et al. 2001) studied the influence of pulse-on-time, voltage, pulse-off-time and electric current on the speed and roughness after WEDM of $\mathrm{Al}_{2} \mathrm{O}_{3}$ and $\mathrm{SiC}$ particles reinforced Al-MMCs. The surface roughness rises with the rise of voltage, released energy and pulse-on-time. It was also noted that the type of reinforcement affects the machining speed. The highest speeds of machining of $\mathrm{Al}_{2} \mathrm{O}_{3}$ and SiC reinforced MMCs are around 6.5 and 3 times smaller than that of corresponding matrix material alone. Guo et al. (Guo, Wang et al. 2002) investigated 20 vol.\% $\mathrm{Al}_{2} \mathrm{O}_{3}$ particle reinforcement Al6061-MMCs by EDM at higher wire speed. Minor influence of the electrical parameters on surface roughness was noted in this investigation. Machining efficiency is improved by higher voltage, pulse-on-time and current. Yan et al. (Yan, Tsai et al. 2005) performed WEDM on 6061AlMMCs reinforced with 10 and 20 vol.\% $\mathrm{Al}_{2} \mathrm{O}_{3}$ particle as well as on matrix 6061Al alloy. The machining speed during machining of matrix materials was highest among all workpieces. The increase of the reinforcement volume fraction causes breakage of wire, narrower slit, rougher surface finish and wider/deeper craters on the wire surface. In the case of $20 \mathrm{vol} . \% \mathrm{Al}_{2} \mathrm{O}_{3}$ reinforced $\mathrm{MMCs}$, the wire shifted due to impedance by protruding of reinforcement particles in the slit which causes bandings on the machined surface under low wire tension. Thus, frequency of wire breakage limits the machining speed of composites. However, Seo-Kim et al. (Seo, Kim et al. 2006) noted higher wear when volume percentage is lower which is contradictory to the results obtain by other researcher (Patel, Pandey et al. 2008).

Too high electrical resistivity of engineering ceramics, such as $\mathrm{ZrO}_{2}, \mathrm{Al}_{2} \mathrm{O}_{3}$ or $\mathrm{Si}_{3} \mathrm{~N}_{4}$ hinders the EDM process of these materials. In order to use the advantages of the EDM process, a secondary electrically conductive phase, such as $\mathrm{WC}$, $\mathrm{TiCN}, \mathrm{TiB}_{2}, \mathrm{ZrC}$, or $\mathrm{TiN}$ can be added to obtain a composite that is electrically conductive enough to allow EDM machining (König, Dauw et al. 1988, Martin, Cales et al. 1989, Pitman and Huddleston 2000, Kozak, Rajurkar et al. 2004, Bonny, De Baets et al. 2008). Many studies on the EDM for conductive ceramic composites have been carried out (Liu 2003). The surface integrity of the EDMed specimens decreased with increasing current (Jianxin and Taichiu 2000). The mean surface texture improved as the discharge energy was reduced (Mordecai and Huddleston 1995). Martin et al. (Martin, Cales et al. 1989) have reported that $\mathrm{TiN} / \mathrm{Si}_{3} \mathrm{~N}_{4}$ composites are more easily machined than tungsten carbide and the tool consumption is lower. $\mathrm{ZrO}_{2}$-based composites with 40 vol. \% WC, $\mathrm{TiC}_{0.5} \mathrm{~N}_{0.5}$ or $\mathrm{TiN}$ phase addition have proven to be appropriate for wire EDM in demineralised water. The material removal mechanism was due to melting and evaporation. The machined surface consists of recast layer, resolidified droplets and voids as well as a micro-crack network. The surface roughness could be reduced by one third after 
consecutive EDM finish cutting. Amongst the $\mathrm{ZrO}_{2}$-based composites, $\mathrm{ZrO}_{2}-\mathrm{WC}$ exhibited better performance in EDM machinability (MRR and surface quality) and higher mechanical properties (strength, hardness and toughness), compared to $\mathrm{ZrO}_{2}-\mathrm{TiN}$ and $\mathrm{ZrO}_{2}-\mathrm{TiCN}$ composites with equal volumetric secondary phase content (Bonny, De Baets et al. 2008). Pitman and Huddleston (Pitman and Huddleston 2000) applied a conductive silver coating over TiN reinforced $\mathrm{Si}_{3} \mathrm{~N}_{4}$ composite workpiece surface. This coating reduced the drop voltage in workpiece material; thereby decreased energy loss. The conductive silver coating not only minimizes the variation in resistance but also it increases the productivity of the process. The clamp position changes the cutting velocity significantly. As the cut approaches the clamp, there was an increase in MRR. A reduction in MRR occurs when the wire moves away from the clamp. Hence, it was found that actual MRR depends on the individual machining geometry and relative position of wire electrode with respect to clamping. Liu (Liu 2003) investigated microstructure and conductivity of $\mathrm{TiN} / \mathrm{Si}_{3} \mathrm{~N}_{4}$ ceramic composites after electrical discharge machining (EDM). The wear rate of the electrode increases with increasing current in EDM process. The electrode wear rate of brass is higher than that of copper electrode. The wire surface was covered with resolidified-layer formation films. The wear surfaces of copper and brass electrodes are similar to those found after EDM process. These indicate that the erosion of tool electrode surface is smooth at EDM cutting. The sinker-EDM at higher pulse energy causes severe micro-damage in the surface. The micro-cracks are formed on the TiN grain boundaries of $\mathrm{TiN} / \mathrm{Si}_{3} \mathrm{~N}_{4}$ composites, which may play a role in toughening ceramics. The surface roughness was found to have greater dependence on pulse energy and, it also increases with the increase of pulse energy (Liu 2003).

The literature review discussed above indicates that the available research works on WEDM are concentrated on the effect of machining parameters, spark energy and wire tension on the wire rupture, surface finish of the machined parts, MRR as well as the theory and experimental verification of crater formation on workpieces. So far, there is no published work on degradation of wire electrode during machining of MMCs though it is imperatively needed to have proper understanding on the dimensional accuracy of the machined parts as well as mechanism of WEDM. Therefore the present work investigates the role of different machining parameters on the degradation of wire electrodes during machining of Al-MMCs reinforced with different sizes of SiC particles.

\section{Experimental}


A series of WEDM of particle reinforced MMCs (with varying particle size) were carried out by FANUC ROBOCUT $\alpha$-0iD machine. The metal matrix composites were made of 6061 aluminum alloy reinforced with $10 \mathrm{vol}$. \% SiC particles. Three different reinforcement sizes were used: $13 \mu \mathrm{m}$, $3 \mu \mathrm{m}$ and $0.7 \mu \mathrm{m}$. In addition, unreinforced 6061 aluminum matrix material was also machined under similar condition to understand the effect of reinforcement as well as size of reinforcement. During WEDM process, the following fixed parameters were employed: wire speed of $10 \mathrm{~m} / \mathrm{min}$, wire tension of 1200 gf, flushing rate of $10 \mathrm{l} / \mathrm{min}$, open circuit voltage $85 \mathrm{~V}$, servo voltage $44 \mathrm{~V}$ and holediameter of $12 \mathrm{~mm}$. A brass wire with $0.25 \mathrm{~mm}$ of diameter and coated with zinc was used as wire electrode. Additional experiments were also carried out by varying pulse-on-time and wire tension to investigate the effect of pulse-on-time and wire tension on degradation of wire for MMCs reinforced with bigger $(13 \mu \mathrm{m})$ and smaller $(0.7 \mu \mathrm{m})$ particles. Details of the experimental conditions are given in table 1.The machining conditions were selected based on the data presented in literature [15-18] and the existing facilities in the laboratory. A slot of $9 \mathrm{~mm}$ long and $12 \mathrm{~mm}$ width was produced on a plate of $137 \times 42 \times 9 \mathrm{~mm}^{3}$ in each experiment. Several slots were produced in each workpiece under similar machining condition.

Table 1: Design of experiments.

\begin{tabular}{cccc}
\hline $\begin{array}{c}\text { Exp. } \\
\text { No. }\end{array}$ & Size of the reinforcement & Wire tension (gf) & Pulse-on-time $(\mu \mathrm{s})$ \\
\hline 1 & $13 \mu \mathrm{m}$ & 1200 & 4 \\
2 & $3 \mu \mathrm{m}$ & 1200 & 4 \\
3 & $0.7 \mu \mathrm{m}$ & 1200 & 4 \\
4 & $-($ matrix material) & 1200 & 4 \\
& & & 4 \\
5 & $13 \mu \mathrm{m}$ & 1800 & 4 \\
1 & $13 \mu \mathrm{m}$ & 1200 & 4 \\
6 & $13 \mu \mathrm{m}$ & 600 & 4 \\
& & & 4 \\
7 & $0.7 \mu \mathrm{m}$ & 1800 & 4 \\
3 & $0.7 \mu \mathrm{m}$ & 1200 & 4 \\
8 & $0.7 \mu \mathrm{m}$ & 600 & 3 \\
& & & 2 \\
9 & $13 \mu \mathrm{m}$ & 1800 & 4 \\
10 & $13 \mu \mathrm{m}$ & 1800 & 3 \\
7 & $13 \mu \mathrm{m}$ & 1800 & \\
11 & & 1800 & \\
& $0.7 \mu \mathrm{m}$ & 1800 &
\end{tabular}


After WEDM, wire surfaces as well as wire cross-sections were investigated by Quanta 450 (FEI) SEM equipped with energy dispersive x-ray analysis (EDX). Cross-section samples were prepared by mounting the wires in resin followed by standard metallographic sample preparation procedure with final polishing in colloidal silica. Care was taken to ensure that the wires stand vertical in mounted resin.

\section{Result and discussion}

\subsection{Effect of reinforcement size on wire shape}

WEDM is a discontinuous process where thousands of electric sparks take part in material removal process by vaporising and melting the workpiece. The electric sparks not only remove workpiece material but also affect the dimensions of wire electrode. Cross-section SEM micrograph of different wires after WEDM is shown in Fig. 1 as well as the cross-section of virgin (unused) wire for comparison purpose. It is clear from Fig. 1 that, the diameter of wire electrode changes during EDM process. In fact, the original circular cross-section (Fig. 1a) becomes oval shapes regardless of workpiece material type. It indicates that permanent deformation of the wire occurs due to high temperature and possible interaction with the electrolyte and melted workpiece materials.

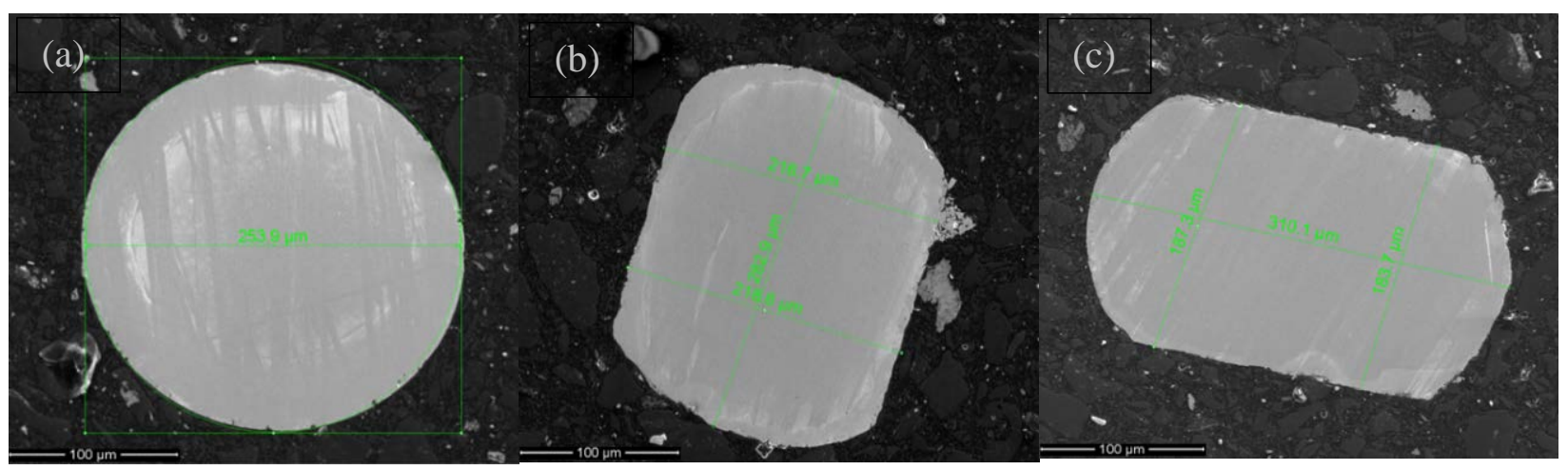



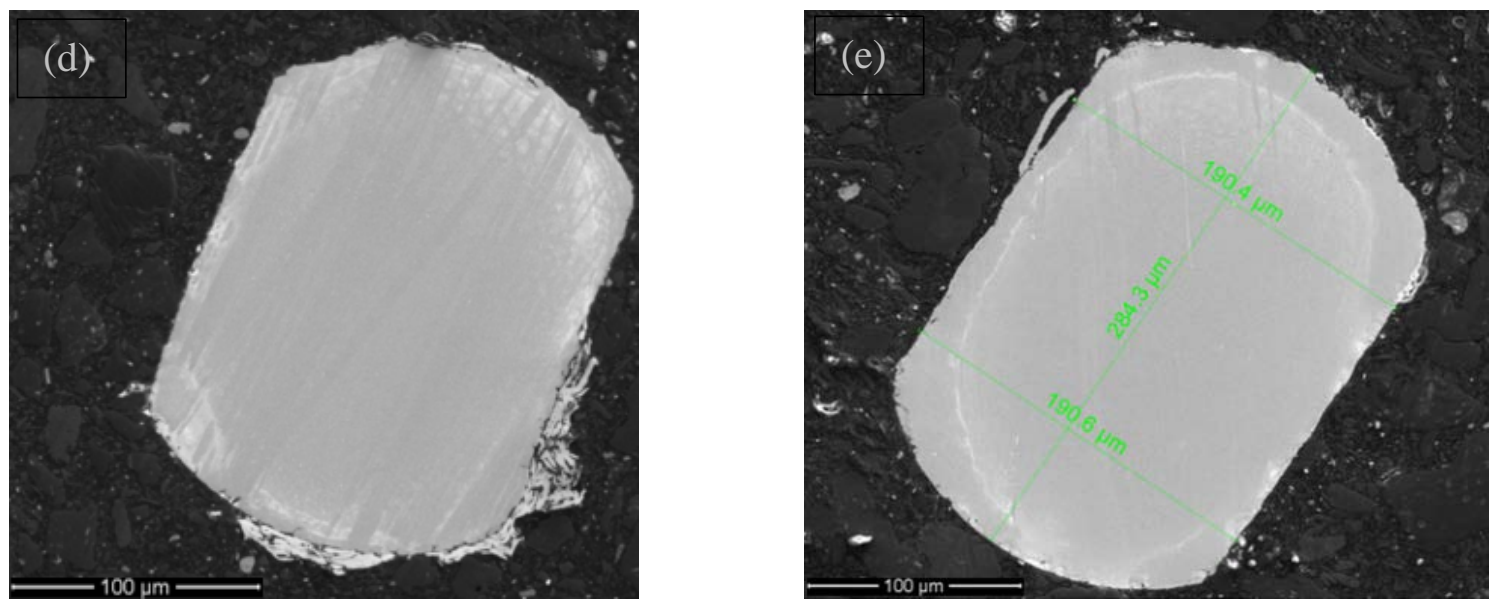

Fig. 1 : Cross-section SEM micrograph of virgin (unused) wire (a) and wires after WEDM of different workpieces: (b) matrix material, (c) $0.7 \mu \mathrm{m}$, (d) $3 \mu \mathrm{m}$ and (e) $13 \mu \mathrm{m} \mathrm{SiC}$ reinforced MMCs.

The possible mechanism of wire deformation has shown schematically in Fig. 2. Two types of wire movement takes place simultaneously during the WEDM process: cutting speed at which the wire moves into the workpiece and wire speed at which the wire moves from the top to the bottom of the workpiece under certain tension. The wire starts to degrade as soon as the EDM process starts due to high temperature and the degradation continues as the wire moves inside and came out from the bottom of the workpiece. Fig. 3 shows the evolution of the shape of the wire cross-section at different positions of wire with respect to workpiece: (i) slot generation at the start of machining (Fig. 3a), (ii) during machining when most of the part of the wire section is inside the slot (Fig. 3b), and (iii) when the wire is completely in the slot (Fig. 3c). At the start of the machining, only a small part of the wire periphery takes part in the machining and experience high temperature which provides minor deformation when the wire reaches at the bottom of the slot (Fig. 3d). The machining continues and the width of the kerf increase. At this stage, the material removal takes place along the length as well as width directions of the kerf until the full diameter full diameter of the wire moves into the workpiece. During this time, the wire is pushed forward to maintain the spark gap at the most advanced point and sides of the wire are pressed and most of the wire deformation takes place as shown in Fig. 3(e). At certain stage, the spark gap between sides of the wire and kerf wall reduces which generates higher temperature in three sides of the wire and facilitates further wire deformation. After the initial feed, WEDM process stabilizes and wire shape changes as shown in the Fig. 3 (f) as the machining continues. 


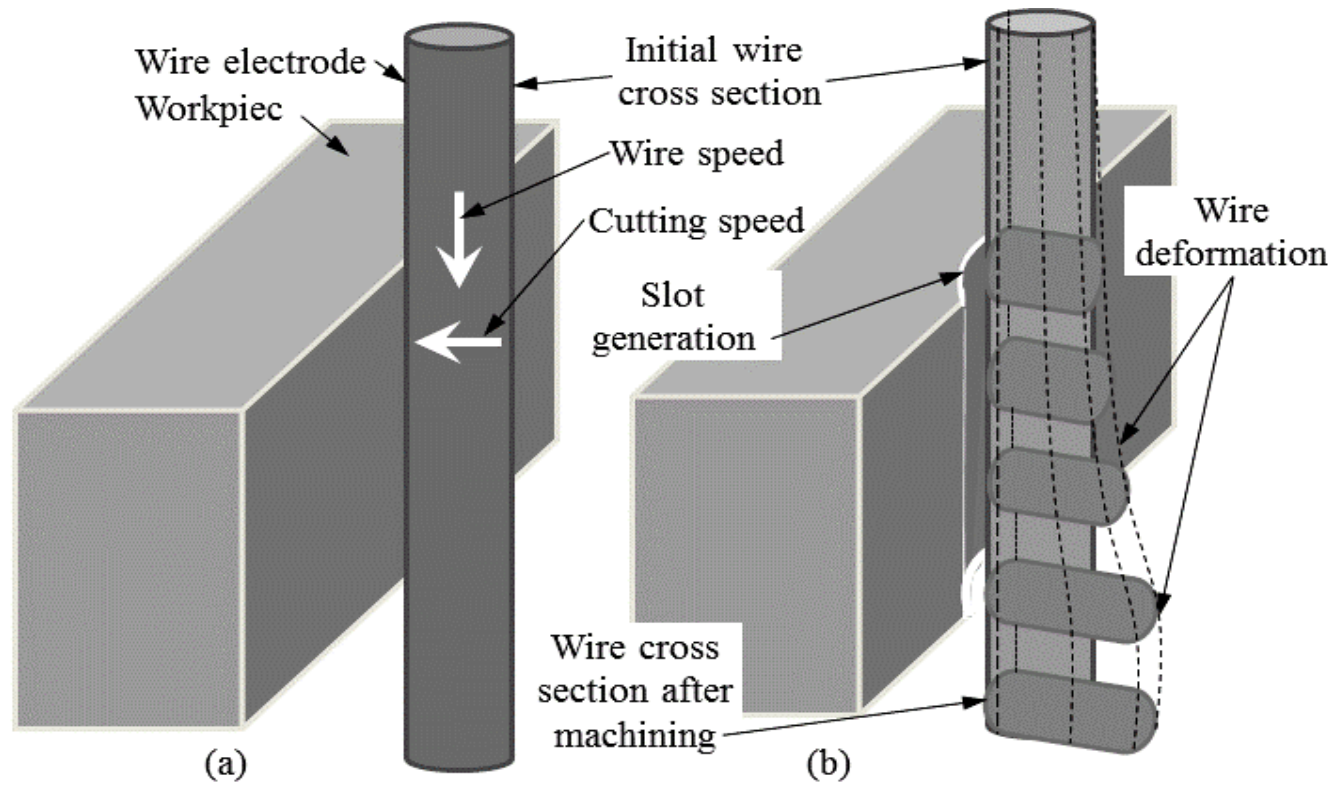

Fig. 2: Typical WEDM process with wire deformation: before (a) and during (b) machining process.

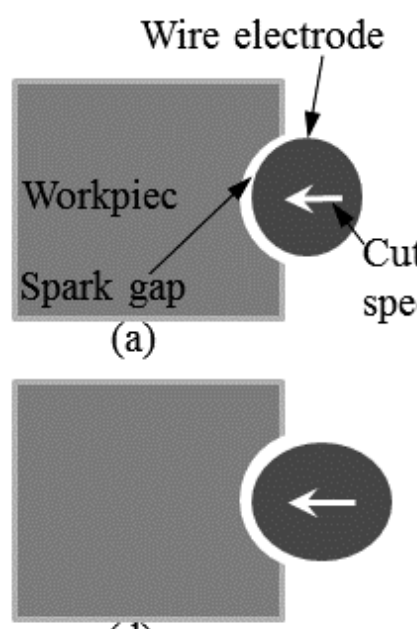

(d)

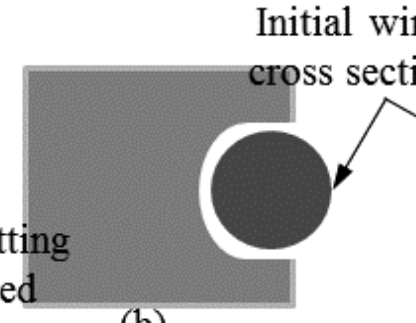

(b)

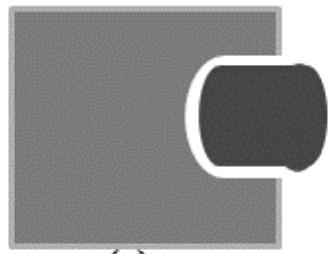

(e)

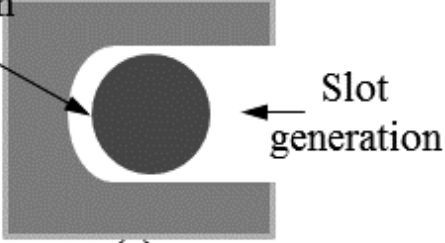

(c)

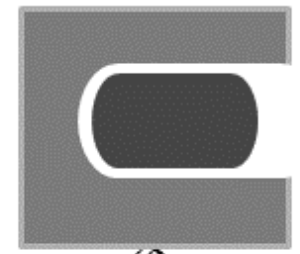

(f)

Fig. 3: Possible wire deformation mechanism during EDM process: (a-c) process view from top and (d-f) process view from the bottom at different machining stages: start of machining (a, d), majority portion of wire is inside the slot (b, e) and wire is completely inside the slot (c, f).

The cross-sectional area and periphery of virgin (unused) wire as well as wires after machining of different types of workpieces were measured and plotted in Fig. 4. It shows that, net variations of cross-sectional areas of wires are insignificant after machining. The variation of the cross-section and perimeter of the wire depend mainly on the generated temperature and not on the workpieces being machined for the machining conditions considered in this section, i.e. wire tension of 1200 gf and 4 $\mu$ s pulse-on-time. 


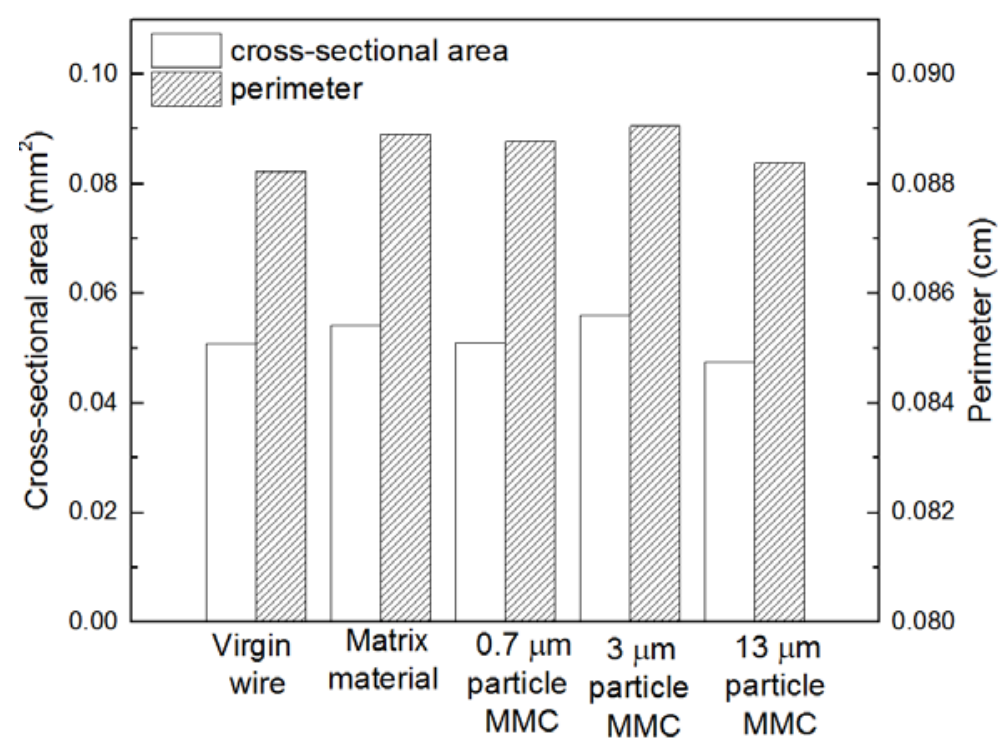

Fig. 4: Cross-section and perimeter of wires after WEDM with 1200 gf wire tension and $4 \mu$ s pulseon-time. Data of virgin (unused) wire were included in the graph for comparison purpose.

\subsection{Effect of the wire tension on wire shape}

The effect of wire tension on the deformation of wire in terms of cross-sectional area evolution is shown in Figures 5 and 6 for bigger $(13 \mu \mathrm{m})$ and smaller $(0.7 \mu \mathrm{m})$ particle reinforced MMCs, respectively. Though the shape of the wires after deformation is similar, however the cross-section area and perimeter are different. The cross-sectional area and periphery of wires after machining of these two types of MMCs have plotted with respect to wire tension in Fig. 7. For both parameters, these are smaller for MMC reinforced with smaller particles $(0.7 \mu \mathrm{m})$ than that with bigger particles $(13 \mu \mathrm{m})$ at lower wire tension (600 gf). With the increase of wire tension both of these parameters for both materials decrease and then start to increase with further increase of wire tension. It is interesting to note that, at higher wire tension the cross-sectional area and periphery for the MMC reinforced with bigger particles are higher than that of smaller particles. Therefore, there is a critical wire tension for which minimum wire deformation occurs. In this case it is close to $1100 \mathrm{gf}$. In fact, the size of the reinforcements affects the wire deformation during EDM process as bigger reinforced particles cause higher deformation to the wire at low wire tension (Fig. 7). At low wire tension, the wire is more flexible and bigger particles slow down the material removal rate as shown by Pramanik et al.(Pramanik 2015). With the increase of wire tension, the wire becomes less flexible and the length of the wire employed for machining reduces which accounts relatively less heat experience by the wire and thus decrease wire deformation. With further increase of wire tension, the wire becomes more rigid and capable of removing reinforcing particles attached to the workpiece. Thus, conductive fresh matrix is exposed frequently and more electric sparks are generated which leads to higher 
temperature generation and eventually causes higher wire deformation. The MMCs with smaller reinforcing particles have larger conductive matrix material surface for electric spark which generates higher temperature than that of bigger particle reinforced MMCs. Thus, wire gets higher deformation during machining of MMCs with smaller reinforced particles compare to that of bigger ones.

The brass wire, which was employed in present machining process, has very good malleability as well as low melting point (1173-1213 K). Therefore, the flow ability of the wire increases with the increase of temperature. Moreover, it can have a downward flow under gravity during machining at higher temperature. The discrete downward flow has profound effect on the bottom of the workpiece. Vaporization of the wire electrode also occurs to some extent during wire EDM process. Thus super positioning of these two mechanisms decides the cross-sectional area of the wires at the end of the machining.
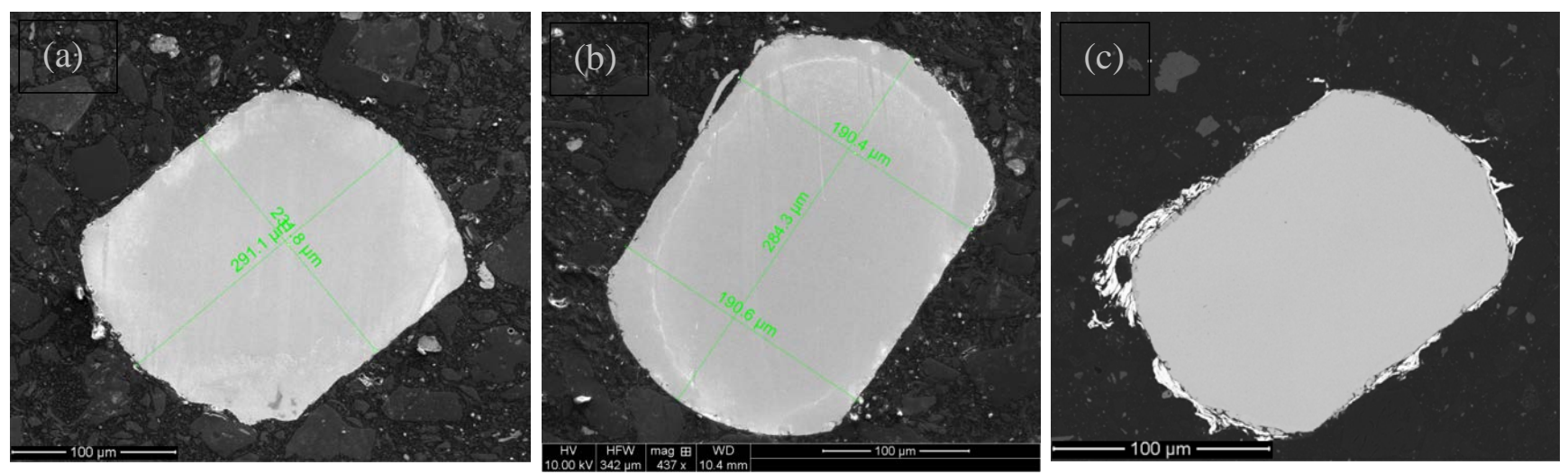

Fig. 5: Cross-section SEM micrograph of wire electrode after WEDM of bigger (13 $\mu \mathrm{m})$ particles reinforced MMCs at different wire tension : (a) 1800 gf, (b) 1200 gf and (c) 600 gf.
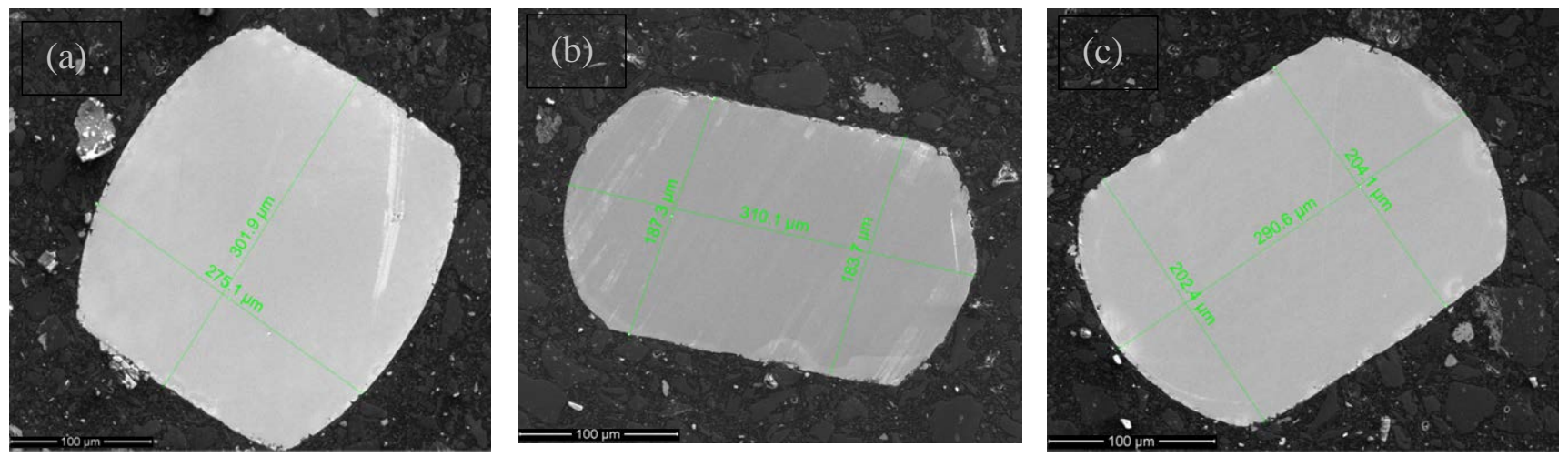

Fig. 6: Cross-section SEM micrograph of wire electrode after WEDM of smaller $(0.7 \mu \mathrm{m})$ particles reinforced MMCs at different wire tension : (a) 1800 gf, (b) 1200 gf and (c) 600 gf. 


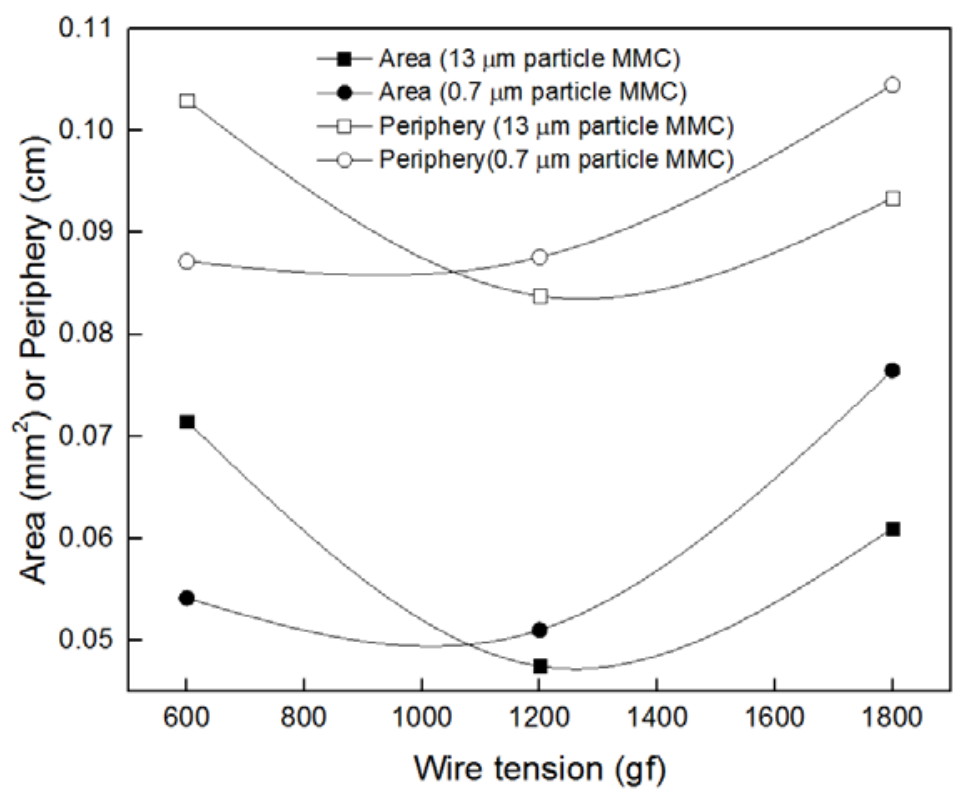

Fig. 7: Effect of wire tension on wire cross-section and periphery after machining different types of MMCs at $4 \mu$ s pulse-on-time

\subsection{Effect of pulse-on-time on wire shape}

SEM micrographs on cross-section of deformed wires after WEDM of $0.7 \mu \mathrm{m}$ and $13 \mu \mathrm{m} \mathrm{SiC}$ particles reinforced MMCs at various pulse-on-times are shown in Figures 8 and 9 respectively. Fig. 10 presents the effect of pulse-on-time on cross-section area and periphery evolution of the deformed wire at wire tension of 1800 gf. Cross-sectional area and periphery follow the similar trend with the variation of pulse-on-time. At lower pulse-on-time, the cross sectional areas of the deformed wire are almost identical for both MMCs. With the increase of pulse-on-time, cross-section areas increase for both materials due to the increase of temperature as mentioned in previous sections. However, the rate of increase of wire cross-sectional area is higher for MMCs reinforced with smaller particles compare to that of bigger particles (Fig. 10). MMCs with smaller reinforcement have larger conductive matrix material surface for electric spark which generates higher temperature than that of bigger particle reinforced MMCs. Thus, wire gets higher deformation during machining of MMCs with smaller reinforced particles compared to that of bigger ones. 

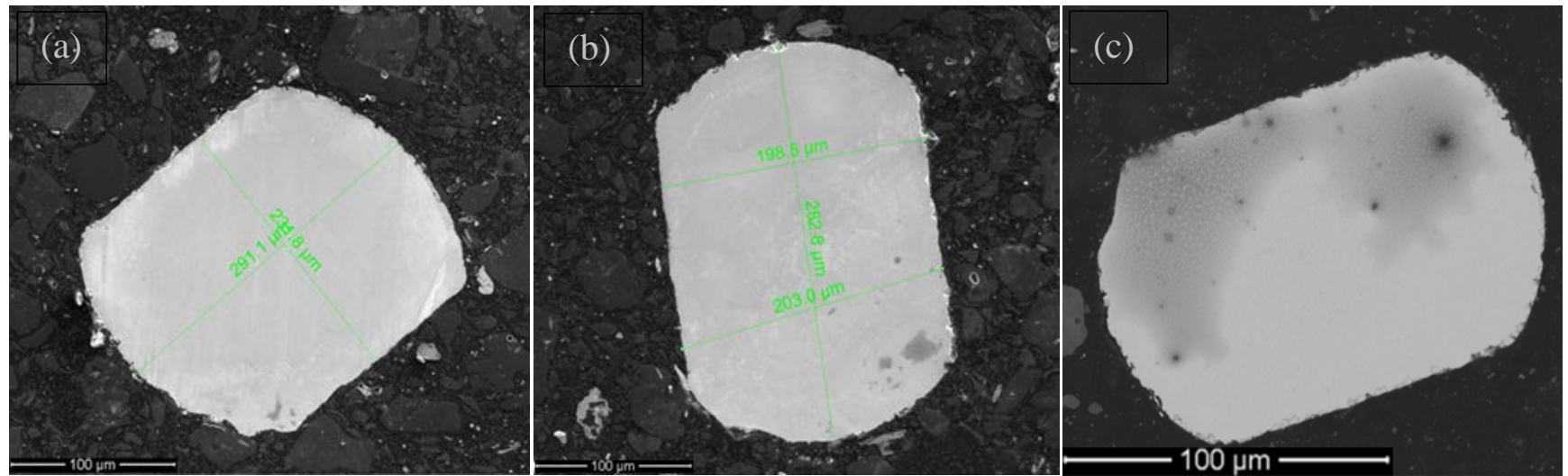

Fig. 8: Cross-section SEM micrograph of wire electrode after WEDM of bigger (13 $\mu \mathrm{m})$ particles reinforced MMCs at different pulse-on-time at 1800 gf wire tension: (a) $4 \mu \mathrm{s}$, (b) $3 \mu \mathrm{s}$ and (c) $2 \mu \mathrm{s}$.
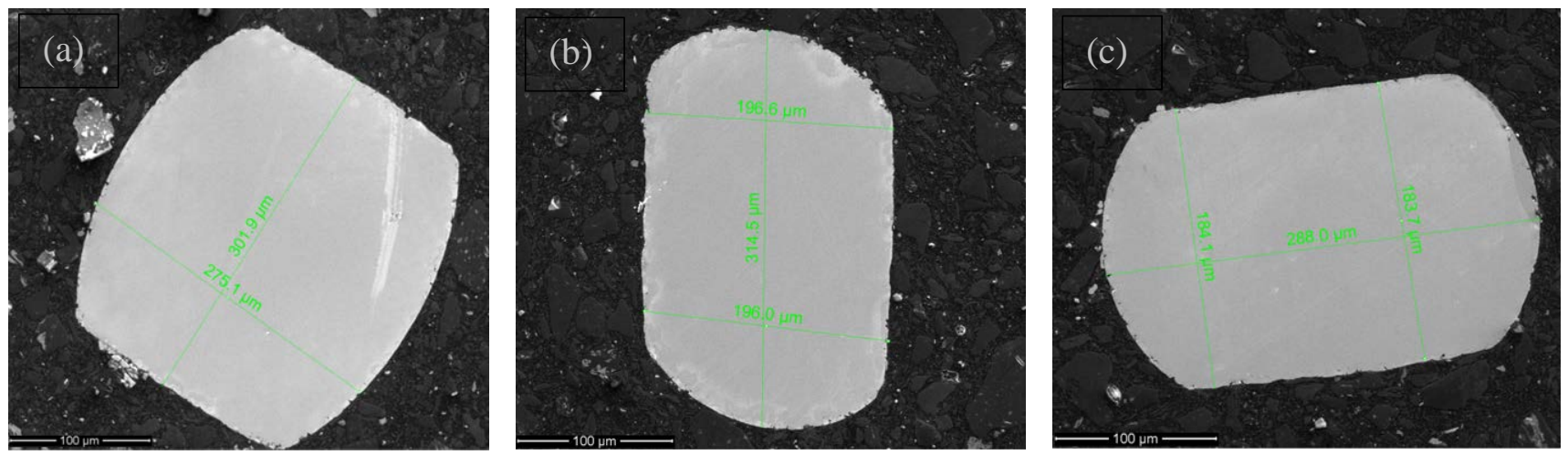

Fig. 9: Cross-section SEM micrograph of wire electrode after WEDM of smaller $(0.7 \mu \mathrm{m})$ particles reinforced MMCs at different pulse-on-time at 1800 gf wire tension: (a) $4 \mu \mathrm{s}$, (b) $3 \mu \mathrm{s}$ and (c) $2 \mu \mathrm{s}$.

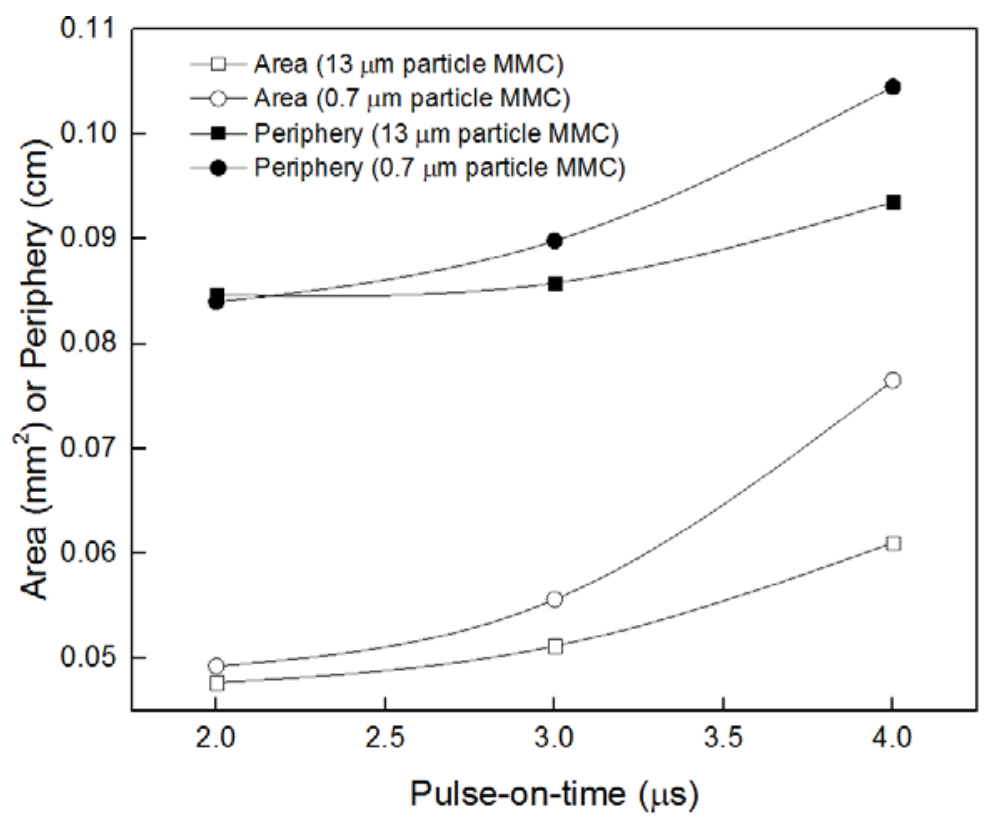

Fig. 10: Effect of pulse-on-time on wire cross-section and periphery after WEDM of different MMCs at 1800 gf wire tension. 


\subsection{Morphology of wire electrode}

Longitudinal top-view of virgin (unused) wire together with chemical composition (EDX analysis) is shown in Fig. 11(a). The wire surface is coated with Zn particles as evident by EDX analysis. The wire surface as well as composition changes after WEDM process and these changes depend on the position of the wire surface with respect to workpieces during the WEDM process. Schematic of typically deformed wire electrode is shown in Fig. 11(b). The periphery of the wire can be divided as follows, depending on the cutting direction: (i) front edge, (ii) rare edge and (iii) side edges.

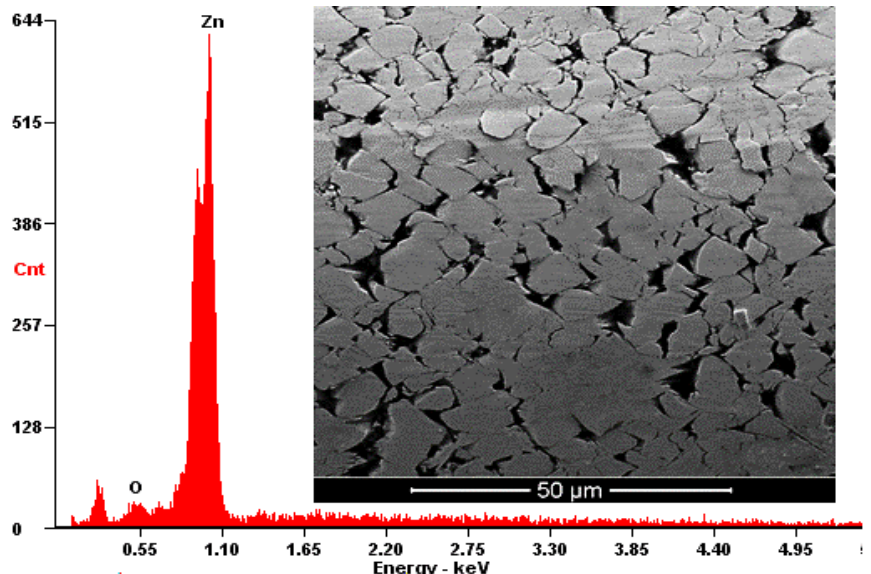

(a)

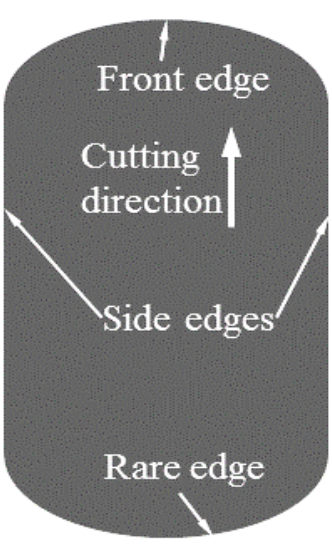

(b)

Fig. 11: Longitudinal top-view of virgin (unused) wire together its chemical composition (a) and schematic of typically deformed wire (b).

As shown previously in Figures 2 and 3, the front edge of the wire mainly takes part in material removal process where higher temperature is generated. Fig. 12 shows the SEM image as well as chemical composition of wire surface at the front edge. Heavy deformations alongside wear marks are evident as a result of machining process. Zn grains became elongated and contain wear marks as the front edge of the wire surface goes through discrete but millions of simultaneous electric sparks. This also reduces the possibility to deposit workpiece material on it as clearly evident by EDX analysis (Fig. 12). The rare edge (Fig. 11b) of the wire electrode does not take part in material removal process and thus reduces the possibility of wire failure by holding it together. This is the least damaged side of the wire electrode as shown in Fig. 13 together with its chemical composition. Minor structural changes are noted and no workpiece material is attached to the surface. 


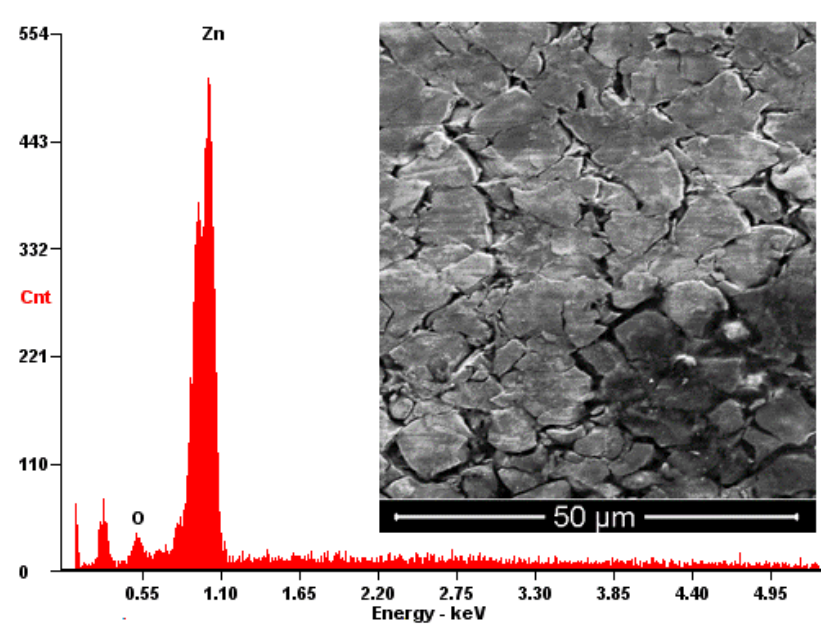

Fig. 12: SEM image of front edge of wire surface after WEDM together with its chemical analysis.

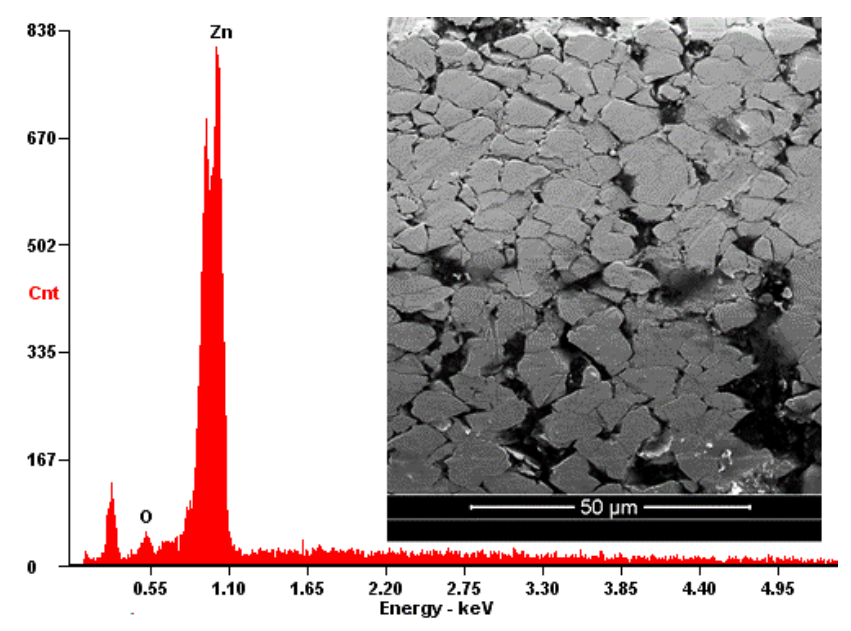

Fig. 13: SEM image of rare edge of wire surface after WEDM together with its chemical analysis.

The side edges of the wire electrode as shown in Fig. 11(b) don't take part in material removal process significantly; though help to smooth up the kerf surfaces by removing smaller amount of materials as discontinuous electric sparks take place at a lower rate in this area. There are chances that protrudes of reinforcements may scratch the side edges (Pramanik 2014). Thus a variety of surface appearance is expected as shown in Figures 14 and 15 and presence of aluminium and silicon is noted which came from the workpiece material and adhesion of the workpiece materials on the wire surface is clearly visible (Fig. 14). The adhesion of workpiece material on the wire occurs during sparking due to spattering of molten metal (Pramanik 2015). In addition, the occurrence of electric spark is non-uniform and inconsistence, which causes inconsistence presence of workpiece material on the wire electrode. For example, Fig. 15 shows the presence of aluminium and silicon on the wire surface from EDX analysis though these are not clearly visible on the surface. Most probably, the workpiece materials sit between Zn grains. In addition to that, wear of the zinc grains in the wire surface is also visible. The folds on the wire surface in Fig. 15 may be due to the wire deformation mechanism described in Fig. 3(e). 


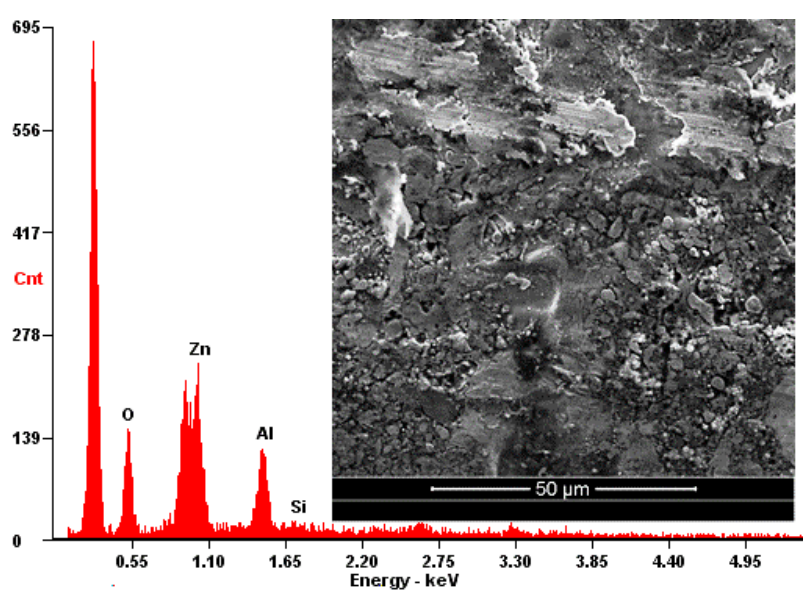

Fig. 14: SEM image of side edge of wire surface, with visible workpiece material, after WEDM and its chemical analysis.

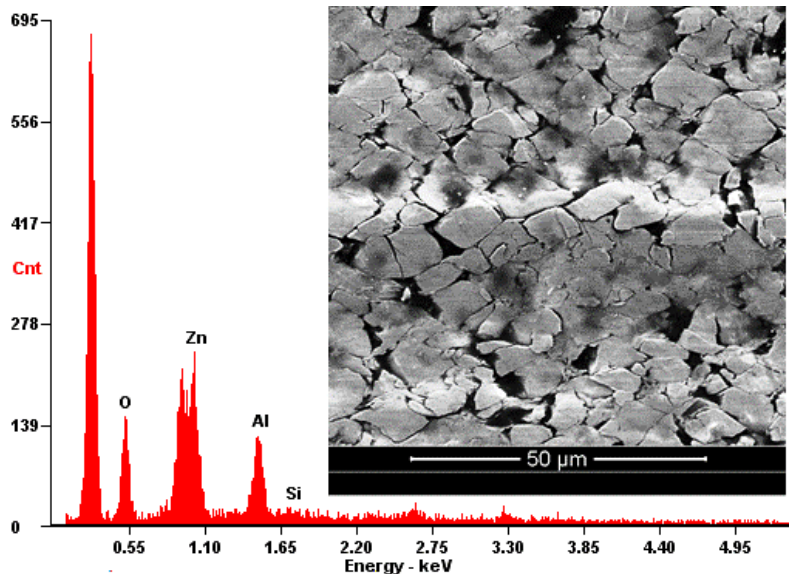

Fig. 15: SEM image of side edge of wire surface, without any visible workpiece material, after

WEDM and its chemical analysis.

The deformation of the wire firstly affects the kerf width and it depends on the width (distance between side edges) of the wire cross-sectional area. The width of the wire cross-section area varies with the machining conditions, machining time and workpiece materials. It is not necessary that the width of the wire cross-section is always smaller than that of wire diameter. It is reported that, kerf width at the top of the workpiece is always bigger than that of bottom (Pramanik 2015, Pramanik 2015). This is due to continuous change of wire cross-section shape/area. Thus, a constant kerf width is impossible to achieve which affects the accuracy and tolerance of machined parts. The wire electrode does not stay circular any more after machining; therefore the term 'electrode diameter after machining' does not exist.

\section{Conclusions}

The present paper investigates the effect of reinforcement size on the degradation of wire during WEDM of SiC reinforced Al-based MMCs. In addition, it analysed the effect of machining parameters and interaction between machining parameters and size of the reinforcements. The following conclusions can be made based on the present investigation:

(a) The wire deforms in a shape which is no longer circular but consists of curved front and rare edges, and two straight side edges irrespective of cutting conditions and workpiece materials.

(b) The cross-sectional area of the wires after WEDM varies with the machining conditions as well as with the size of reinforcing particles in the MMCs. 
(c) The evolution of cross-sectional area of the wire is decided by balancing two mechanisms: (i) downward flow of highly malleable soften wire material due to high temperature which increases the diameter of wire electrode, and (ii) vaporisation of the wire material at higher temperature which reduces the diameter of wire electrode. These complex processes are affected by machining conditions as well as workpiece materials. The variation of cross-sectional dimension of the wire affects the accuracy of the machined parts.

(d) Once the WEDM process stabilised, the front edge of the wire section takes part in material removal, the side edges smooth up the kerf wall and rare edge reduces the chance of the soften wire electrode to fail.

\section{References}

Agrawal, S. S. and V. Yadava (2013). "Modeling and prediction of material removal rate and surface roughness in surface-electrical discharge diamond grinding process of metal matrix composites." Materials and Manufacturing Processes 28(4): 381-389.

Bonny, K., P. De Baets, J. Vleugels, A. Salehi, O. Van der Biest, B. Lauwers and W. Liu (2008). "Influence of secondary electro-conductive phases on the electrical discharge machinability and frictional behavior of $\mathrm{ZrO}$ 2-based ceramic composites." journal of materials processing technology 208(1): 423-430.

Guo, Z. N., X. Wang, Z. G. Huang and T. M. Yue (2002). "Experimental investigation into shaping particle-reinforced material by WEDM-HS." Journal of Materials Processing Technology 129(1-3): 56-59.

Ho, K. and S. Newman (2003). "State of the art electrical discharge machining (EDM)." International Journal of Machine Tools and Manufacture 43(13): 1287-1300.

Hung, N. P., L. J. Yang and K. W. Leong (1994). "Electrical discharge machining of cast metal matrix composites." Journal of Materials Processing Technology 44(3-4): 229-236.

Jianxin, D. and L. Taichiu (2000). "Surface integrity in electro-discharge machining, ultrasonic machining, and diamond saw cutting of ceramic composites." Ceramics International 26(8): 825-830. König, W., D. Dauw, G. Levy and U. Panten (1988). "EDM-future steps towards the machining of ceramics." CIRP Annals-Manufacturing Technology 37(2): 623-631.

Kozak, J., K. P. Rajurkar and N. Chandarana (2004). "Machining of low electrical conductive materials by wire electrical discharge machining (WEDM)." Journal of Materials Processing Technology 149(1): 266-271.

Lal, S., S. Kumar, Z. Khan and A. Siddiquee (2013). "An investigation on effects of wire electrical discharge machining parameters on surface roughness of newly developed hybrid metal matrix composite." Proceedings of the Institution of Mechanical Engineers, Part B: Journal of Engineering Manufacture: 0954405413506703.

Liu, C.-C. (2003). "Microstructure and tool electrode erosion in EDMed of TiN/Si 3 N 4 composites." Materials Science and Engineering: A 363(1): 221-227.

Liu, J. W. and Y. Z. Wu (2014). "An Orthogonal Experimental Analysis of WEDM-HS of Al2O3 Particle-Reinforced Aluminum Alloy 6061 with 10-Vol\% Al2O3." Advanced Materials Research 910: 61-64. 
Liu, J. W., T. M. Yue and Z. N. Guo (2009). "Wire Electrochemical Discharge Machining of Al2O3 Particle Reinforced Aluminum Alloy 6061." Materials and Manufacturing Processes 24(4): 446-453. Maher, I., A. A. Sarhan and M. Hamdi (2014). "Review of improvements in wire electrode properties for longer working time and utilization in wire EDM machining." The International Journal of Advanced Manufacturing Technology: 1-23.

Martin, C., B. Cales, P. Vivier and P. Mathieu (1989). "Electrical discharge machinable ceramic composites." Materials science \& engineering. A, Structural materials: properties, microstructure and processing 109: 351-356.

Meena, K. L. M., A.; Banwait, S.S.; Jaswanti. (2013). "Parametric effects during nonconventional machining of PR-AL-SiC-MMC's by CNC wire cut EDM." International Journal of Engineering and Innovative Technology 3(1): 341-345.

Mordecai, N. and J. Huddleston (1995). "Spark erosion of an electroconductive SiC ceramic matrix composite containing TiB2." British ceramic transactions 94(4): 161-164.

Muller, F., J. Monaghan and I. Verein Deut (1998). Electro discharge machining of a particle reinforced metal matrix composite. 12th International Symposium for Electromachining. 1405: 513522.

Patel, K., P. M. Pandey and P. V. Rao (2008). "Understanding the role of weight percentage and size of silicon carbide particulate reinforcement on electro-discharge machining of aluminium-based composites." Materials and Manufacturing Processes 23(7): 665-673.

Pitman, A. and J. Huddleston (2000). "Electrical discharge machining of ZrO2/TiN particulate composite." British ceramic transactions 99(2): 77-84.

Pramanik, A. (2014). "Developments in the non-traditional machining of particle reinforced metal matrix composites." International Journal of Machine Tools and Manufacture 86: 44-61.

Pramanik, A. (2015). "Electrical Discharge Machining of MMCs Reinforced with Very Small Particles." Materials and Manufacturing Processes(just-accepted).

Pramanik, A., L. C. Zhang and J. A. Arsecularatne (2006). "Prediction of cutting forces in machining of metal matrix composites." International Journal of Machine Tools and Manufacture 46(14): 17951803.

Pramanik, A. B., A.K.; Islam, M.N. (2015). "Effect of reinforced particle size on wire EDM of MMCs." International Journal of Machining and Machinability of Materials In press.

Pramanik, A. B. A. K. I., M.N.; Littlefair; G. (2015). "Electrical discharge machining of 6061 aluminium alloy." Transactions of Nonferrous Metals Society of China 25(9): xxxxxxx-xxxxxxxx (in press).

Rozenek, M., J. Kozak, L. Dabrowski and K. Lubkowski (2001). "Electrical discharge machining characteristics of metal matrix composites." Journal of Materials Processing Technology 109(3): 367-370.

Saini, V., A. K. Zahid and A. N. Siddiquee (2013). "Optimization of wire electric discharge machining of composite material (Al6061/Sicp) using taguchi method." International Journal of Mechanical and Production Engineering 2.

Seo, Y., D. Kim and M. Ramulu (2006). "Electrical discharge machining of functionally graded 1535 vol\% SiCp/Al composites." Materials and Manufacturing Processes 21(5): 479-487.

Tosun, N. and C. Cogun (2003). "An investigation on wire wear in WEDM." Journal of materials processing technology 134(3): 273-278.

Yan, B. H., H. C. Tsai, F. Y. Huang and L. C. Lee (2005). "Examination of wire electrical discharge machining of $\mathrm{Al}(2) \mathrm{O}(3) \mathrm{p} / 6061 \mathrm{Al}$ composites." International Journal of Machine Tools \& Manufacture 45(3): 251-259. 
